\title{
ERRATUM
}

\section{Estuaries: A Lifeline of Ecosystem Services in the Western Indian Ocean}

\author{
Salif Diop, Peter Scheren, and John Machiwa
}

(C) Springer International Publishing Switzerland 2016

S. Diop et al. (eds.), Estuaries: A Lifeline of Ecosystem Services in the Western Indian Ocean, Estuaries of the World, DOI 10.1007/978-3-319-25370-1

DOI 10.1007/978-3-319-25370-1_21

Copyright Page, Chapter 1 and Chapter 20: Salif Diop's affiliation was incorrect in the previous version. It has now been corrected as given below.

National Academy of Sciences and Techniques - Section of Agricultural Sciences and Université Cheikh Anta Diop de Dakar, Dakar-Fann, Senegal 